\title{
Early associations with palatable foods in overweight and obesity are not disinhibition related but restraint related
}

Citation for published version (APA):

Werrij, M. Q., Roefs, A. J., Janssen, I., Wolters, G., Hospers, H. J., Jansen, A. T. M., Mulkens, S., \& Stapert, D. (2009). Early associations with palatable foods in overweight and obesity are not disinhibition related but restraint related. Journal of Behavior Therapy and Experimental Psychiatry, 40(1), 136-146. https://doi.org/10.1016/j.jbtep.2008.07.003

Document status and date:

Published: 01/01/2009

DOI:

10.1016/j.jbtep.2008.07.003

Document Version:

Publisher's PDF, also known as Version of record

Document license:

Taverne

Please check the document version of this publication:

- A submitted manuscript is the version of the article upon submission and before peer-review. There can be important differences between the submitted version and the official published version of record.

People interested in the research are advised to contact the author for the final version of the publication, or visit the DOI to the publisher's website.

- The final author version and the galley proof are versions of the publication after peer review.

- The final published version features the final layout of the paper including the volume, issue and page numbers.

Link to publication

\footnotetext{
General rights rights.

- You may freely distribute the URL identifying the publication in the public portal. please follow below link for the End User Agreement:

www.umlib.nl/taverne-license

Take down policy

If you believe that this document breaches copyright please contact us at:

repository@maastrichtuniversity.nl

providing details and we will investigate your claim.
}

Copyright and moral rights for the publications made accessible in the public portal are retained by the authors and/or other copyright owners and it is a condition of accessing publications that users recognise and abide by the legal requirements associated with these

- Users may download and print one copy of any publication from the public portal for the purpose of private study or research.

- You may not further distribute the material or use it for any profit-making activity or commercial gain

If the publication is distributed under the terms of Article $25 \mathrm{fa}$ of the Dutch Copyright Act, indicated by the "Taverne" license above, 


\title{
Early associations with palatable foods in overweight and obesity are not disinhibition related but restraint related
}

\author{
Marieke Q. Werrij ${ }^{\mathrm{a}, *}$, Anne Roefs ${ }^{\mathrm{b}}$, Inge Janssen ${ }^{\mathrm{b}}$, Daphne Stapert ${ }^{\mathrm{b}}$, \\ Gert Wolters $^{\mathrm{c}}$, Sandra Mulkens ${ }^{\mathrm{b}}$, Harm J. Hospers ${ }^{\mathrm{a}}$, Anita Jansen ${ }^{\mathrm{b}}$ \\ a Department of Work and Social Psychology, Maastricht University, The Netherlands \\ ${ }^{\mathrm{b}}$ Department of Clinical Psychological Science, Maastricht University, The Netherlands \\ ${ }^{\mathrm{c}}$ Atrium Medical Center, Brunssum, The Netherlands
}

\section{A R T I C L E I N F O}

\section{Article history:}

Received 3 July 2006

Received in revised form 20 June 2008

Accepted 17 July 2008

\section{Keywords:}

Palatable foods

Disinhibition

Restraint

Obesity

Semantic priming paradigm

Indirect measures

\begin{abstract}
A B S T R A C T
Obese people prefer and overconsume high-fat foods. At the same time they often attempt to lose weight. In two studies we investigated relations between palatable high-fat food words and disinhibition related concepts (study 1 ) and palatable high-fat food words and restraint related concepts (study 2) within the semantic priming paradigm. In study 1, 24 overweight/obese and 19 healthy weight women participated. There was no association between palatable high-fat food words and disinhibition. In study 2, 27 obese and 29 healthy weight women participated. The presentation of palatable high-fat food words facilitated the accessibility of restraint related concepts as hypothesized, but independent of weight status. Clearly, early associations with palatable high-fat food words are restraint related in both healthy weight and obese people.
\end{abstract}

(c) 2008 Elsevier Ltd. All rights reserved.

\section{Introduction}

In industrialized countries palatable high-fat foods are easily available. Especially for obese people it is a challenge to appropriately manage the abundance of these foods, as they have been found to be more sensitive to the fattiness and palatability of foods than people of healthy weight. Obesity has been associated with both a preference and elevated consumptions of high-fat foods (e.g., Drenowski, 1991,

\footnotetext{
* Corresponding author. Maastricht University, Faculty of Psychology, Department of Work and Social Psychology, P.O. Box 616, 6200 MD Maastricht, The Netherlands. Tel.: +31 43388 4046; fax: +31 433884211.

E-mail address: m.werrij@psychology.unimaas.nl (M.Q. Werrij).
} 
1997; Rissanen et al., 2002). Furthermore, obese people are more responsive to the palatability of foods, as they were repeatedly found to consume more of palatable foods than healthy weight controls in laboratory settings (but little evidence was found for obese people eating less of unpalatable food; for a review see Pliner, Herman, \& Polivy, 1990).

To achieve weight loss, obese people frequently attempt to reduce their energy intake and thus to restrain their eating behaviour. Restraint theory (Herman \& Polivy, 1984) posits that restrained eaters have their own self-imposed diet boundary, in contrast to unrestrained eaters who do not have such a boundary. While normal, unrestrained eaters eat until they are satiated, restrained eaters stop eating when their diet boundary is reached. Exceeding this boundary leads to disinhibition and overeating. This phenomenon of counterregulation has been investigated extensively in several laboratory studies, and in support of the disinhibition hypothesis, restrained eaters were indeed found to disinhibit after disruptions in self-control such as eating or anticipating a (perceived) high caloric preload, while unrestrained eaters were not (for a review see Ruderman, 1986). However, restrained eaters also showed disinhibited eating in situations in which self-control was not released, such as merely smelling high caloric food (Jansen \& Van den Hout, 1991), or when a negative mood was induced (Baucom \& Aiken, 1981; Chua, Touyz, \& Hill, 2004; Frost, Goolkasian, Ely, \& Blanchard, 1982). Thus, the precise mechanism underlying the proposed phenomenon of disinhibition is still not clear. Furthermore, though dieting and binging are associated, not much support has been found for the assumed causal relation between these two (Stice, 2002).

In sum, obese people prefer high-fat foods and they tend to overconsume them (Drenowski, 1991, 1997; Rissanen et al., 2002). Considering most obese people's wish to lose weight, eating too much fat is not recommended. Furthermore, although we cannot pronounce upon causality, overeating in those people who try to restrain their eating behaviour is not uncommon. It is therefore an interesting question what causes (obese) people to disinhibit in the presence of palatable foods. According to cognitive theory, cognitions play a crucial role in triggering behaviour. Accordingly, dysfunctional (automatic) cognitions are assumed to underlie several forms of psychopathology (Beck, 1976), and cognitions might play a significant role in disturbed eating behaviour as well (e.g., Cooper \& Fairburn, 1992; Nauta, Hospers, Kok, \& Jansen, 2000). So possibly, the presence of palatable high-fat foods elicits disinhibiting thoughts in obese people, causing them to overeat. In the present study this relation between palatable foods and disinhibition is investigated on a cognitive level. That is, we investigated whether concepts of palatable foods and disinhibition were related in obese and healthy weight women.

In earlier studies, cognitions were measured explicitly by the use of self-report measures (e.g., Cooper, Cohen-Tovée, Todd, Wells, \& Tovée, 1997), interviews (e.g., Nauta, Hospers, Jansen, \& Kok, 2000), thought listing procedures (e.g., Boon, Stroebe, Schut, \& Jansen, 1998) or the taping of thoughts (e.g., Hickford, Wards, \& Bulik, 1997; Jansen, Merckelbach, Oosterlaan, Tuiten, \& van den Hout, 1988). The use of self-report measures, however, has several shortcomings. First, participants' responses might be strategically controlled and susceptible to demand characteristics. Second, behaviour is not always preceded by deliberate considerations, but in some cases follows from spontaneous and relatively automatic processes. In the latter case, self-report measures may not be appropriate (e.g., De Houwer, 2002, 2003; De Jong, Pasman, Kindt, \& van den Hout, 2001). In the present study, cognitions were investigated by an indirect measure. Indirect means that a participant is not directly asked for an evaluation or association. Instead, task performance informs us about the participants' evaluations or associations. An advantage of indirect measures is that influences of social desirability and possibilities for participants to strategically control their responses are minimized (De Houwer, 2006).

Following Zack, Toneatto, and MacLeod (1999), we used the semantic priming paradigm (Neely, 1991 ) to study the cognitive associations between the concepts of interest (i.e., palatable foods and disinhibition). In this paradigm two word stimuli, a prime followed by a target, are presented on the computer screen in quick succession. Participants are urged to decide as quickly as possible whether the target is a word or a nonword (i.e., a lexical decision task). If semantic priming occurs, lexical decisions to a target word are faster and more accurate when prime and target are related than when they are not. Thus, participants are faster to decide that butter is a word when it is preceded by bread than when it is preceded by doctor. If the concepts of palatable foods and disinhibition are semantically related, priming with one concept will facilitate responding to the other. It is therefore expected that 
participants will respond faster to a disinhibition target (e.g., to stuff) when it is preceded by a palatable food prime (e.g., chocolate), than when the target is preceded by a neutral prime (e.g., lamp). We expect this effect to be more pronounced in overweight/obese participants than in a control group of healthy weight participants (hypothesis 1). It is furthermore expected that participants will respond faster to a palatable food target when it is preceded by a disinhibition prime than when it is preceded by a neutral prime. Again, we expect this effect to be more pronounced in overweight/obese participants than in participants of healthy weight (hypothesis 2 ).

\section{Study 1}

\subsection{Method}

\subsubsection{Participants}

Twenty-four overweight and obese women (BMI > 27) and 19 healthy weight women (BMI 19-25) participated in this study. Participants were recruited by advertisements in a local newspaper. Inclusion criteria were BMI (overweight/obese group BMI >27, control group BMI 19-25) and age (19-60 years). Exclusion criteria were pregnancy and the presence of apparent medical conditions (thyroid gland problems) responsible for obesity. Furthermore, healthy weight participants were excluded if they scored 15 or higher on the Restraint Scale (RS; Herman \& Polivy, 1980). Overweight/obese and healthy weight participants were matched on age.

\subsubsection{Overview semantic priming paradigm}

During the task, prime and target words were presented on the computer screen in quick succession. Participants had to perform a lexical decision task upon presentation of the target (word/nonword). Stimuli were presented in blocks per target type. In block type A, primes were palatable foods or neutral words, targets were disinhibition words or nonwords. In block type B, primes were disinhibition or neutral words, targets were palatable foods or nonwords. Lexical decisions were made by pressing the left or the right button on an external key-box (key-assignment was counterbalanced over participants). The dependent variable was the key-press latency in response to the target.

\subsubsection{Stimulus selection and timing of the trials}

Stimuli selection. Palatable foods and disinhibition related words were selected in a pilot study. ${ }^{1}$ The goal of this pilot study was to find (1) generally liked high-fat foods and (2) words covering the disinhibition concept. Sixty-four students completed the palatable food part of the pilot study (vegetarians were left out of the analyses), 67 students completed the part concerning disinhibition related words. Similar to Zack et al. (1999), we based our neutral words on two categories, in the present study being "things you find in a living room" and "things you find in an office". Neutral words were matched to food and disinhibition stimuli on objective frequency of occurrence in print (Celex Lexical Database, Dutch frequency lemma's) and number of letters. Living room words were matched to palatable foods; office words were matched to disinhibition words. Selected stimuli are presented in the Appendix.

Construction of nonwords. Following Zack et al. (1999), nonwords were obtained by matching each word with a word of equal frequency of occurrence in print and number of letters, and then randomly replacing a vowel and a consonant in the matched word.

Timing of a trial. At the beginning of each trial, a fixation stimulus $(++++)$ was presented for $250 \mathrm{~ms}$, followed by a blank screen $(250 \mathrm{~ms})$, presentation of the prime $(750 \mathrm{~ms})$, and presentation of the target (until response), following the procedure used by Zack et al. (1999). The inter trial interval was $1000 \mathrm{~ms}$.

Randomization of stimuli. In total, 212 trials were presented. The first 20 trials were practice trials containing stimuli that did not appear in the actual task. Practice trials were followed by four

${ }^{1}$ Detailed information about the selection of the stimuli can be obtained from the first author. 
experimental blocks, in each of which 48 trials were presented. Block type A (disinhibition targets) contained two prime-target conditions: (1) neutral-disinhibition and (2) palatable food-disinhibition. Block type B (palatable food targets) contained two other prime-target conditions: (3) neutralpalatable food and (4) disinhibition-palatable food. In each block, half of the primes were neutral, and half of the targets were words. Within each block, trials were presented in a unique random order for each participant. Order of part A and B was counterbalanced over participants.

\subsubsection{Stimuli check}

To check the palatability of the high-fat palatable foods, participants rated the palatable food stimuli on palatability $(1=$ dislike a lot to $7=$ like a lot). None of the food stimuli was considered unpalatable by the participants, with chocolate having the highest score on palatability $(M=6.0)$ and hamburger the lowest score $(M=4.5)$. Next, disinhibition words and palatable foods were rated on familiarity. Participants had to indicate how often they thought they had heard or seen the word $(1=$ never to $7=$ very often). Participants were relatively more unfamiliar with disinhibition words $(M=3.5)$ than with palatable foods $(M=5.0), t(42)=7.17, P<0.001$. However, palatable food primes and disinhibition primes appeared in separate target conditions, with their matched neutral words as primes.

\subsubsection{Procedure}

Participants were tested individually. Upon entering the laboratory, participants were provided with general information about the study and after signing the informed consent form, they were seated in front of the computer. Instructions for the task were presented on the computer screen and if needed elucidated orally. Participants were instructed to read the prime, but only respond to the target. They had to decide as quickly as possible, while avoiding making too many mistakes, whether the target was a word or a nonword by pressing the corresponding key on an external key-box. After the practice trials, participants were asked to write down as many primes as they could remember. This free recall task was only administered to ensure continued attention to the primes, and data of the free recall task were not analyzed. Before the beginning of the experimental trials, the instructions were repeated on the monitor. Then the four experimental blocks were presented. After each block, participants could take a short break. At the end of the computer task participants had to perform another free recall task, similar to the previous one. Finally, the stimuli check questionnaires were administered and body height and weight were measured. Before leaving the research room, participants were debriefed, paid $€ 10$, and asked not to talk about the purpose of the study with others.

\subsubsection{Design and analyses}

Data were analyzed separately for each target type (disinhibition vs. palatable food). For trials with disinhibition targets, a 2 (group: overweight/obese vs. healthy weight) $\times 2$ (prime: neutral vs. palatable food) ANOVA was performed (hypothesis 1 ). For trials with palatable food targets, a 2 (group: overweight/obese vs. healthy weight) $\times 2$ (prime: neutral vs. disinhibition) ANOVA was performed (hypothesis 2). Prior to the analyses of the semantic priming task, participants in the two groups were compared on relevant characteristics (age, BMI, Restraint Scale) by $t$-tests.

\subsection{Results}

\subsubsection{Participant characteristics}

Based on the criterion ( $\geq M+3 \mathrm{SD}$ ) for the percentage of responses that were either erroneous, too fast (RT $<100 \mathrm{~ms}$ ) or too slow (RT $>3000 \mathrm{~ms}$ ), none of the participants had to be excluded.

Mean age of the overweight/obese group was 42 years ( $S D=10.3$, range $21-58)$, mean age of the control group was 41 years ( $S D=12.0$, range $21-56$ ). The groups did not differ significantly on age, $t(41)<1$. Mean BMI of the overweight/obese group was 33.7 ( $\mathrm{SD}=5.6$, range 27.3-49.6), mean BMI of the control group was 22.1 ( $\mathrm{SD}=1.6$, range 19.6-24.8). BMI differences between the groups were 
Table 1

Mean response latencies (SE) in ms to disinhibition targets and palatable food targets

\begin{tabular}{|c|c|c|c|c|}
\hline & \multicolumn{2}{|c|}{ Target disinhibition (hypothesis 1 ) } & \multicolumn{2}{|c|}{ Target palatable food (hypothesis 2) } \\
\hline & Prime neutral & Prime palatable food & Prime neutral & Prime disinhibition \\
\hline Healthy weight & $646.5(29.1)$ & $654.3(28.3)$ & $617.6(27.9)$ & $628.1(30.0)$ \\
\hline Obese & $691.6(25.9)$ & $688.3(25.2)$ & $657.3(24.8)$ & $666.3(26.7)$ \\
\hline
\end{tabular}

obviously significant, $t(27.5)=9.75 P<0.001$. Mean score on the RS was 15.7 ( $S D=3.7$, range $9-23$ ) in the overweight/obese group and $8.1(\mathrm{SD}=2.7$, range $4-12)$ in the control group. RS scores differed significantly between the groups, $t(41)=7.50, P<0.001$.

\subsubsection{Analyses priming task}

Analyses were performed for the dependent variables response latency (speed) and percentage of errors (accuracy). Response latencies for responses that were either too fast (RT $<100 \mathrm{~ms}$ ) or too slow (RT $>3000 \mathrm{~ms}$ ) were discarded $(0.4 \%$ of the responses). Response latencies for error responses were also discarded (2.3\% of the responses). Because analyses on the percentage of errors did not reveal any significant effects, only analyses on response latencies will be reported. ${ }^{2}$ The mean response latencies and standard errors are presented in Table 1.

Results for disinhibition targets (hypothesis 1). It was hypothesized that participants would respond faster to a disinhibition target after a palatable food prime than after a neutral prime, and that this effect would be most pronounced in the overweight/obese group. No support for this hypothesis was found: there was no main effect of prime, $F(1,41)<1$, and no interaction between group and prime, $F(1,41)<1$. The main effect of group was not significant either, $F(1,41)=1.10, P=0.30$.

Results for palatable food targets (hypothesis 2). No support was found for our second hypothesis that participants would respond faster to a palatable food target after a disinhibition prime than after a neutral prime, and that this would be most pronounced in the overweight/obese group. There was no main effect of prime, $F(1,41)=2.19, P=0.15$, and no group $\times$ prime interaction, $F(1,41)<1$. The main effect of group was not significant either, $F(1,41)=1.04, P=0.31$.

\subsection{Discussion}

In the present study, we examined the association between the concepts of palatable foods and disinhibition in overweight/obese and healthy weight participants in a semantic priming paradigm. The hypothesized cognitive association between the concepts of palatable foods and disinhibition was not found. Although several factors could have caused the nonsignificant findings, it is not likely that the semantic priming paradigm was chosen inaccurately. We thoroughly followed the procedure used by Zack and colleagues (Zack et al., 1999) in their study on the association of negative affective cues and alcohol concepts in problem drinkers. They predicted negative affective cues to activate alcohol concepts, and vice versa, in problem drinkers with high psychiatric distress, but not in problem drinkers with low psychiatric distress. They found support for these hypotheses. The paradigm therefore seems appropriate for examining the cognitive association between two related concepts in a clinical population.

Possibly, the hypothesized association between palatable foods and disinhibition was not found because early associations with high-fat palatable foods are already directed at the negative health related consequences of these foods. Neumark-Sztainer et al. (2000) found that more than half of their study population engaged in some kind of weight control behaviour. This suggests that weight control is an issue for a large percentage of the population. Particularly overweight and obese people may know that high-fat foods are very unhealthy and fattening. Therefore, instead of disinhibition related associations, these palatable foods may have elicited restraint associations. In a second study, it will be

\footnotetext{
${ }^{2}$ Analyses were also performed on the log transformed latencies. These analyses did not lead to different results.
} 
tested whether palatability is associated with restraint, using the same paradigm as in study 1 . Furthermore, to enlarge the contrast between the two weight groups, only obese people will be included (BMI $>30$ ) in this second study. We expect that participants will respond faster to a restraint target when it is preceded by a palatable food prime, than when the target is preceded by a neutral prime. We expect this effect to be more pronounced in obese participants than in a control group of healthy weight participants (hypothesis 3 ). We furthermore expect that participants will respond faster to a palatable food target when it is preceded by a restraint prime than when it is preceded by a neutral prime. Again, we expect this effect to be more pronounced in obese participants than in participants of healthy weight (hypothesis 4).

\section{Study 2}

\subsection{Method}

\subsubsection{Participants}

Twenty-eight obese women (BMI $>30$ ) and 29 women of healthy weight (BMI 19-25) participated in this study. Like in study 1 , healthy weight participants were recruited by advertisements in a local newspaper. In study 2 however, obese women were recruited through the Department of Medical Psychology of the Atrium Medical Center Brunssum, a hospital in the south of the Netherlands. Women announcing for bariatric surgery, and visiting the hospital psychologist for a psychological screening, were invited to participate in the study. The BMI inclusion criterion for the obese group was 30 or more, the other inclusion and exclusion criteria were the same as in study 1 . Obese and healthy weight participants again were matched on age.

\subsubsection{Overview semantic priming paradigm}

The same semantic priming task was used as in study 1 . In block type A, primes now were palatable foods or neutral words, targets were restraint words or nonwords. In block type B, primes were restraint or neutral words, targets were palatable foods or nonwords.

\subsubsection{Stimulus selection and timing of the trials}

Selection of the stimuli. Palatable food words and living room words were the same as in study 1. Restraint words were selected by a pilot study $(n=42)$ similar to that in study $1 .{ }^{1}$ Based on the pilot study, the twelve words that were most representative for the concept of restraint were selected (see Appendix). A new set of office words was composed and matched to restraint stimuli on objective frequency of occurrence in print and number of letters. Nonwords were constructed in the same way as in study 1 .

Timing of a trial and randomization of stimuli. Trial timing and stimuli randomization was the same as in study 1 . The four prime-target conditions were (1) neutral-restraint, (2) palatable food-restraint, (3) neutral-palatable food, (4) restraint-palatable food.

\subsubsection{Stimuli check}

Food preferences and subjective familiarity with palatable food and restraint words were measured on a seven-point scale (see study 1). None of the food stimuli was considered unpalatable by the participants, with French fries having the highest score on palatability $(M=6.1)$ and doughnut ball the lowest score $(M=4.6)$. Participants were as familiar with restraint words $(M=5.0)$ as with palatable foods $(M=4.8), t(51)=1.65, P=0.11$.

\subsubsection{Procedure}

The experiment took place in a research room at the Atrium Medical Center Brunssum. The procedure was identical to study 1.

\subsubsection{Design and analyses}

Analyses were similar to those of study 1 . Data were analyzed separately for each target type (restraint vs. palatable food). For trials with restraint targets, a 2 (group: obese vs. healthy weight) $\times 2$ 
(prime: neutral vs. palatable food) ANOVA was performed (hypothesis 3). For trials with palatable food targets, a 2 (group: obese vs. healthy weight) $\times 2$ (prime: neutral vs. restraint) ANOVA was performed (hypothesis 4).

\subsection{Results}

\subsubsection{Participant characteristics}

One (obese) participant was excluded from analyses because of a high percentage ( $\geq M+3 \mathrm{SD}$ ) of errors or responses that were either too fast $(\mathrm{RT}<100 \mathrm{~ms})$ or too slow $(\mathrm{RT}>3000 \mathrm{~ms})$, on the semantic priming task. So, results were analyzed for 27 obese and 29 healthy weight women.

Mean age of the obese group was 37 years $(S D=8.9$, range $22-57)$, mean age of the control group also was 37 years $(S D=8.5$, range $20-55)$. The groups did not differ significantly on age, $t(54)<1$. Mean BMI of the obese group was 40.3 ( $S D=7.5$, range 30.1-65.6), mean BMI of the control group was 22.1 ( $\mathrm{SD}=1.7$, range 18.1-24.8). As expected, BMI differences between the groups were significant, $t(28.6)=12.27, P<0.001$. Mean score on the RS was $18.7(S D=3.8$, range $12-24)$ in the obese group and $8.6(\mathrm{SD}=3.2$, range $2-14)$ in the control group. RS scores differed significantly between the groups, $t(54)=10.85, P<0.001$.

\subsubsection{Analyses priming task}

Analyses were performed for the dependent variables response latency (speed) and percentage of errors (accuracy). Response latencies for responses that were either too fast (RT $<100 \mathrm{~ms}$ ) or too slow (RT $>3000 \mathrm{~ms}$ ) were discarded $(0.2 \%$ of the responses). Response latencies for error responses were also discarded $(0.8 \%$ of the responses). Because analyses on the percentage of errors did not reveal any significant effects, only analyses on response latencies will be reported. ${ }^{2}$ Means are presented in Table 2.

Results for restraint targets (hypothesis 3). It was hypothesized that participants would respond faster to a restraint target after a palatable food prime than after a neutral prime and that this would be most pronounced in the obese group. Supporting our first hypothesis, a significant main effect of prime was found, $F(1,54)=5.23, P<0.03$. Inspection of the means shows that overall, participants responded faster on restraint targets after a palatable food prime than after a neutral prime (see Table 2 for the mean response latencies). However, the expected interaction of group and prime was not significant, $F(1,54)<1$, indicating that this main effect was not qualified by weight status. The main effect of group was not significant either, $F(1,54)<1$.

Results for palatable food targets (hypothesis 4). The data did not support our second hypothesis that participants would respond faster to a palatable food target after a restraint prime than after a neutral prime, and that this effect would be most pronounced in the obese group. The main effect of prime, $F(1,54)=2.63, P=0.11$, and the interaction of group and prime, $F(1,54)=1.63, P=0.21$, were not significant. The main effect of group was not significant either, $F(1,54)<1$.

\subsection{Discussion}

In the second study, we examined the association between the concepts of palatable foods and restraint in obese and healthy weight participants. Supporting our third hypothesis, participants responded more quickly to a restraint target after a palatable food prime than after a neutral prime. However, no difference was found between the obese and healthy weight group. No support was found for the fourth hypothesis, that participants - and obese participants in particular - would respond

Table 2

Mean response latencies (SE) in ms to restraint targets and palatable food targets

\begin{tabular}{|c|c|c|c|c|}
\hline & \multicolumn{2}{|c|}{ Target restraint (hypothesis 3) } & \multicolumn{2}{|c|}{ Target palatable food (hypothesis 4) } \\
\hline & Prime neutral & Prime palatable food & Prime Neutral & Prime Restraint \\
\hline Healthy weight & $799.4(31.3)$ & $785.8(32.4)$ & $760.6(28.4)$ & $785.5(30.1)$ \\
\hline Obese & $790.1(32.4)$ & $768.2(33.6)$ & $787.3(29.4)$ & $790.2(31.2)$ \\
\hline
\end{tabular}


faster to a palatable food target when preceded by a restraint prime than when preceded by a neutral prime.

The presentation of a palatable food word facilitated accessibility of restraint related concepts, as hypothesized. Thus, an association between palatable high-fat food words and restraint was found on a relatively automatic level. Many people know that eating too much high-fat food is bad for one's health and makes one gain weight; explicit attitudes toward high-fat foods in general are more negative than attitudes toward low-fat foods (Stafleu, de Graaf, van Staveren, \& de Jong, 1994). That high-fat foods were found to elicit self-reported restraint related thoughts in restrained as well as in unrestrained eaters (Boon et al., 1998) is in line with the present data. However, this is the first study that shows that the association between high-fat foods and restraint is measurable on a relatively automatic level.

Roefs and Jansen (2002) used an indirect measure to study attitudes toward high-fat foods in obesity. In line with the present results, their healthy weight and obese participants showed a more negative attitude toward high-fat foods than toward low-fat foods on the Implicit Association Test (IAT; Greenwald, McGhee, \& Schwartz, 1998). However, whereas in the present study no group differences were found, on the IAT the relatively negative attitude toward high-fat foods was most pronounced for the obese group (Roefs \& Jansen, 2002). Possibly, these divergent results could be explained by the fact that two very different tasks were used. In the IAT, the fat content of food is made particularly salient because participants have to categorize food items as high-fat or low-fat. In the semantic priming task, fat content was not that salient because participants did not have to focus on the fat content of the presented foods, but on the semantic aspects (word or nonword) of the target items. Moreover, correlations between different indirect measures were found to be surprisingly low, suggesting that they do not measure the same underlying construct (Bosson, Swann, \& Pennebaker, 2000; Olson \& Fazio, 2003).

In sum, high-fat palatable food words facilitated the accessibility of restraint words. The reverse, however, was not true: the concept of restraint did not automatically activate high-fat palatable food words.

\section{General discussion}

Whereas no support was found for an association between palatable high-fat foods and disinhibition concepts (study 1), it was found that palatable food cues activate restraint related concepts (study 2). Apparently, early associations with palatable foods are not disinhibition but rather restraint related. On the early cognitive level, the obese are - like healthy weight people - characterized by associations that point to refraining from eating when confronted with palatable high-fat food words.

A most relevant question, then, is why obese people generally eat more calories than they need, although their early automatic associations are directed at restraining their intake. Recently, it was found that relatively automatic evaluations of food were influenced by the level of reported craving (Roefs et al., 2006); the higher the initial level of craving in obese participants was, the stronger their automatic preference for palatable over unpalatable foods was. Whether obese people's early associations are disinhibition related (rather than restraint related) in situations that elicit craving, remains to be examined. As yet, the most obvious reason for obese people to overeat despite restraint associations is that they can simply not resist the temptation of tasty foods. They know that they should not eat too much, but they are not able to control their eating impulses. Recently, evidence was found for the hypothesis that obese people have difficulties controlling impulses in general (Nederkoorn, Braet, van Eijs, Tanghe, \& Jansen, 2006; Nederkoorn, Smulders, Havermans, Roefs, \& Jansen, 2006). Possibly, this general impulsivity overrides the early restraint associations, and leads to overeating.

Although the present study was carefully designed, there are some critical notes that need to be discussed. First, the observations made in this experiment were on a cognitive level, assuming that (relatively automatic) cognitions play a significant role in determining behaviour (e.g., Beck, 1976). It has, however, repeatedly been shown that cognitions are not always a good predictor of behaviour (e.g., Godin \& Kok, 1996; Orbell, Hodgkins, \& Sheeran, 1997). It must be noted, though, that in these studies cognitions were measured by explicit measures while the present study used an indirect measure aimed at measuring relatively automatic cognitions. Though several studies (Hofmann \& Friese, 2008; 
Hofmann, Rauch, \& Gawronski, 2007) now suggest that spontaneous positive food associations can predict eating behaviour, apparently these food associations are not specifically disinhibition related. Moreover, obese and healthy weight people may not differ in the extent to which they have these associations, but their behaviour may be guided to a stronger degree by these associations. Hofmann and colleagues, for example, showed that automatic associations with M\&Ms only predicted consumption of M\&Ms when participants self-control resources were reduced.

Second, participants of study 1 were recruited from a general population of obese people whereas participants of study 2 were recruited from a subset of obese people: those who announced for bariatric surgery. It could be argued that participants of study 2 were more motivated to lose weight, and perhaps were more preoccupied with concepts of restraint, than the participants of study 1 . However, a study by Neumark-Sztainer et al. (2000) showed that more than 50\% of their study population (mean BMI 27.7) reported current weight control behaviours. It is therefore likely that participants in both studies were motivated to lose weight because of their weight status. Moreover, the association between palatable food words and restraint that was found in study 2 was independent of weight status.

Finally, disinhibition was measured by words that represent a loss of control, and eating to an uncomfortable level of fullness (e.g., "to stuff", "to binge", "to gorge"). It is possible however, that in the obese, overeating is not necessarily characterized by binging, but due to habitual overeating during regular meals and snacks. In that case, cognitions that precede overeating might be related to eating rather than to disinhibition. In a recent study, Papies, Stroebe, and Aarts (2007) found that reading about palatable foods activated hedonic associations in restrained eaters, but not in unrestrained eaters. This suggests that for restrained eaters, eating (palatable foods) is more associated with enjoyment than for unrestrained eaters. It remains to be investigated whether obese people also activate hedonic associations when reading about palatable foods. Moreover, it is also important to test whether these hedonic associations actually precede overeating in both the obese and restrained eaters.

To conclude, the present data show that, at an early level of cognitive processing, palatable high-fat foods are associated with restraint rather than with disinhibition, in both obese and healthy weight people. However, it is certain that the energy balance of obese people is disturbed, which is likely due to overeating. To explain this overeating one should look at other characteristics or precursors in the obese, possibly on a cognitive level.

\section{Appendix}

Studies 1 and 2 Palatable food words. Chocolade (chocolate), chips (chips), friet (fries), croissant (croissant), pizza (pizza), roomijs (ice cream), magnum (magnum), taart (pie), cake (cake), hamburger (hamburger), oliebol (doughnut ball), koek (cookie).

Neutral words A (living room). Kast (closet), bankstel (lounge suit), krukje (stool), kapstok (hat stand), poef (hassock), salontafel (coffee table), lamp (lamp), boekenrek (bookshelf), sofa (sofa), rolluik (roll-down shutter), ladenkast (dresser), deurmat (doormat).

\section{Study 1}

Disinhibition words. Onbeheerst (unrestrained), vreten (to grub), controleverlies (loss of control), vreetbui (eating binge), volstouwen (to gorge), vraatzucht (gluttony), volproppen (to stuff), volstoppen (to cram), vreetpartij (blowout), proppen (to shovel), eetbui (binge), doorslaan (breakdown).

Neutral words B (office). Balpen (ballpoint), bladzijde (page), tekstverwerker (word processor), plakband (sellotape), potlood (pencil), liniaal (ruler), agenda (agenda), beeldscherm (computer screen), printer (printer), nietmachine (stapler), perforator (perforator), inktpatroon (cartridge).

Study 2

Restraint words. Vet (fat), dik (big), afblijven (leave alone), slecht (bad), onverstandig (foolish), calorierijk (high-calorie), lijnen (slim), dieet (diet), kilo (kilo), vermijden (avoid), verboden (forbidden), verkeerd (wrong). 
Neutral words B (office). Balpen (ballpoint), bladzijde (page), inkt (ink), plakband (sellotape), potlood (pencil), liniaal (ruler), agenda (agenda), beeldscherm (computer screen), computer (computer), letter (letter), papier (paper), pen (pen).

\section{References}

Baucom, D. H., \& Aiken, P. A. (1981). Effect of depressed mood on eating among obese and nonobese dieting and nondieting persons. Journal of Personality and Social Psychology, 41, 577-585.

Beck, A. T. (1976). Cognitive therapy and the emotional disorders. New York: International Universities Press.

Boon, B., Stroebe, W., Schut, H., \& Jansen, A. (1998). Food for thought: cognitive regulation of food intake. British Journal of Health Psychology, 3, 27-40.

Bosson, J. K., Swann, W. B., \& Pennebaker, J. W. (2000). Stalking the perfect measure of implicit self-esteem: the blind men and the elephant revisited? Journal of Personality and Social Psychology, 79, 631-643.

Chua, J. L., Touyz, S., \& Hill, A. J. (2004). Negative mood-induced overeating in obese binge eaters: an experimental study. International Journal of Obesity, 28, 606-610.

Cooper, M., Cohen-Tovée, E., Todd, G., Wells, A., \& Tovée, M. (1997). The eating disorder belief questionnaire: preliminary development. Behaviour Research and Therapy, 35, 381-388.

Cooper, M. J., \& Fairburn, C. G. (1992). Thoughts about eating, weight and shape in anorexia nervosa and bulimia nervosa. Behaviour Research and Therapy, 30, 501-511.

De Houwer, J. (2002). The implicit association test as a tool for studying dysfunctional associations in psychopathology: strengths and limitations. Journal of Behavior Therapy and Experimental Psychiatry, 33, 115-133.

De Houwer, J. (2003). A structural analysis of indirect measures of attitudes. In J. Musch, \& K. C. Klauer (Eds.), The psychology of evaluation: Affective processes in cognition and emotion (pp. 219-243). Mahwah, NJ: Lawrence Erlbaum Associates.

De Houwer, J. (2006). What are implicit measures and why are we using them? In R. W. Wiers, \& A. W. Stacy (Eds.), Handbook of implicit cognition and addiction (pp. 11-28) Thousand Oaks, CA: SAGE.

De Jong, P. J., Pasman, W., Kindt, M., \& van den Hout, M. A. (2001). A reaction time paradigm to assess (implicit) complaintspecific dysfunctional beliefs. Behaviour Research and Therapy, 39, 101-113.

Drenowski, A. (1991). Obesity and eating disorders: cognitive aspects of food preference and food aversion. Bulletin of the Psychonomic Society, 29, 261-264.

Drenowski, A. (1997). Taste preferences and food intake. Annual Reviews Nutrition, 17, 237--253.

Frost, R. O., Goolkasian, G. A., Ely, R. J., \& Blanchard, F. A. (1982). Depression, restraint and eating behavior. Behaviour Research and Therapy, 20, 113-121.

Godin, G., \& Kok, G. (1996). The theory of planned behavior: a review of its applications to health-related behaviors. American Journal of Health Promotion, 11, 87-98.

Greenwald, A. G., McGhee, D. E., \& Schwartz, J. L. K. (1998). Measuring individual differences in implicit cognition: the implicit association test. Journal of Personality and Social Psychology, 74, 1464-1480.

Herman, C. P., \& Polivy, J. (1980). Restrained eating. In A. J. Stunkard (Ed.), Obesity (pp. 208-225). Philadelphia, PA: Sauders.

Herman, C. P., \& Polivy, J. (1984). A boundary model for the regulation of eating. In A. J. Stunkard, \& E. Stellar (Eds.), Eating and its disorders (pp. 141-156). New York: Raven Press.

Hickford, C., Wards, T., \& Bulik, C. M. (1997). Cognitions of restrained and unrestrained eaters under fasting and nonfasting conditions. Behavior Research and Therapy, 35, 71-75.

Hofmann, W., \& Friese, M. (2008). Impulses got the better of me: alcohol moderates the influence of implicit attitudes toward food cues on eating behavior. Journal of Abnormal Psychology, 117, 420-427.

Hofmann, W., Rauch, W., \& Gawronski, B. (2007). And deplete us not into temptation: automatic attitudes, dietary restraint, and self-regulatory resources as determinants of eating behavior. Journal of Experimental Social Psychology, 43, 497-504.

Jansen, A., Merckelbach, H., Oosterlaan, J., Tuiten, A., \& van den Hout, M. (1988). Cognitions and self-talk during food intake of restrained and unrestrained eaters. Behavior Research and Therapy, 26, 393-398.

Jansen, A., \& Van den Hout, M. (1991). On being led into temptation: "counterregulation" of dieters after smelling a "preload". Addictive Behaviors, 16, 247-253.

Nauta, H., Hospers, H. J., Jansen, A., \& Kok, G. (2000). Cognitions in obese binge eaters and obese non-binge eaters. Cognitive Therapy and Research, 24, 521-531.

Nauta, H., Hospers, H., Kok, G., \& Jansen, A. (2000). A comparison between a cognitive and behavioral treatment for obese binge eaters and obese non-binge eaters. Behavior Therapy, 31, 441-461.

Nederkoorn, C., Braet, C., van Eijs, Y., Tanghe, A., \& Jansen, A. (2006). Why obese children cannot resist food: the role of impulsivity. Eating Behaviors, 7, 315-322.

Nederkoorn, C., Smulders, F. T. Y., Havermans, R. C., Roefs, A., \& Jansen, A. (2006). Impulsivity in obese women. Appetite, 47, $253-256$.

Neely, J. H. (1991). Semantic priming effects in visual word recognition: a selective review of current findings and theories. In D. Besner, \& G. W. Humphreys (Eds.), Basic processes in reading: Visual word recognition (pp. 264-337). Hillsdale, NJ: Erlbaum.

Neumark-Sztainer, D., Rock, C. L., Thornquist, M. D., Cheskin, L. J., Neuhouser, M. L., \& Barnett, M. J. (2000). Weight-control behaviors among adults and adolescents: associations with dietary intake. Preventive Medicine, 30, 381-391.

Olson, M., \& Fazio, R. H. (2003). Relations between implicit measures of prejudice: what are we measuring? Psychological Science, 14, 636-639.

Orbell, S., Hodgkins, S., \& Sheeran, P. (1997). Implementation intentions and the theory of planned behavior. Personality and Social Psychology Bulletin, 23, 945-954.

Papies, E., Stroebe, W., \& Aarts, H. (2007). Pleasure in the mind: restrained eating and spontaneous hedonic thoughts about food. Journal of experimental Social Psychology, 43, 810-817. 
Pliner, P., Herman, C. P., \& Polivy, J. (1990). Palatability as a determinant of eating: finickiness as a function of taste, hunger, and the prospect of good food. In E. D. Capaldi, \& T. D. Powley (Eds.), Taste, experience, and feeding (pp. 210-226). Washington, DC: APA.

Rissanen, A., Hakala, P., Lissner, L., Mattlar, C.-E., Koskenvuo, M., \& Rönnemaa, T. (2002). Acquired preference especially for dietary fat and obesity: a study of weight-discordant monozychotic twin pairs. International Journal of Obesity, 26, $973-977$.

Roefs, A., \& Jansen, A. (2002). Implicit and explicit attitudes toward high-fat foods in obesity. Journal of Abnormal Psychology, 111, 517-521.

Roefs, A., Quaedackers, L., Werrij, M. Q., Wolters, G., Havermans, R., Nederkoorn, C., et al. (2006). The environment influences whether high-fat foods are associated with palatable or with unhealthy. Behaviour Research and Therapy, 44, 715-736.

Ruderman, A. J. (1986). Dietary restraint: a theoretical and empirical review. Psychological Bulletin, 99, 247-262.

Stafleu, A., de Graaf, C., van Staveren, W. A., \& de Jong, A. A. J. G. (1994). Attitudes towards high-fat foods and their low-fat alternatives: reliability and relationship with fat intake. Appetite, 22, 183-196.

Stice, E. (2002). Risk and maintenance factors for eating pathology: a meta-analytic review. Psychological Bulletin, 128, 825-848.

Zack, M., Toneatto, T., \& MacLeod, C. M. (1999). Implicit activation of alcohol concepts by negative affective cues distinguishes between problem drinkers with high and low psychiatric distress. Journal of Abnormal Psychology, 108, 518-531. 